\section{耍 Heighten Science \\ P U B L I C I T I O N S Corporation ISSN 2575-0194}

\title{
Effect of pre-treatments and drying methods on Moisture percentage of dried Tomato Slices
}

\author{
Pokharkar KK ${ }^{1 *}$, Delvadia DV ${ }^{2}$, Jadhav Parag B ${ }^{3}$ and Bhor $\mathrm{PB}^{4}$ \\ 1,3,4Research Scholar, Department of Horticulture, JAU, Junagadh, Gujarat, India \\ ${ }^{2}$ Professor, Dept. of Horticulture, JAU, Junagadh, Gujarat, India
}

*Address for Correspondence: Pokharkar KK, Research Scholar, Department of Horticulture, JAU, Junagadh, Gujarat, India

Submitted: 08 August 2017

Approved: 11 August 2017

Published: 14 August 2017

Copyright: @ 2017 Pokharkar KK, et al. This is an open access article distributed under the Creative Commons Attribution License, which permits unrestricted use, distribution, and reproduction in any medium, provided the original work is properly cited.

Keywords: Tomato; Slices; Peeling; Blanching; Drying methods; Quality evaluation

\section{ABSTRACT}

A study was undertaken the effect of pretreatments and drying methods on quality parameters of tomato slices with respect to storage using two factors as treatments i.e. 5 pre-treatment levels ( $P_{1}$-Peeled by hot water dip blanching, $P_{2}$-Peeled by hot brine dip blanching, $P_{3}$-Unpeeled by hot water blanching, $\mathrm{P}_{4}$-Unpeeled by hot brine blanching, $\mathrm{P}_{5}$-Control- No peeled and no blanched) and 2 drying methods i.e. ( $\mathrm{D}_{1}$-Tray drying, $\mathrm{D}_{2}$-Sun drying) with completely randomized design of factorial concept with three repetitions at Post Graduate Laboratory of Horticulture Department, College of Agriculture, Junagadh Agricultural University, Junagadh. The quality was evaluated on the basis of physicochemical (i.e. drying time $(\mathrm{h})$ and moisture content (\%) at $1,20,40,60$ and 80 th day of storage. Result of study depicts that the pretreatment $P_{2}$ i.e. peeling of tomato by hot brine dip blanching followed by tray drying $\left(\mathrm{D}_{2}\right)$ recorded minimum $(14.50 \mathrm{~h})$ drying time and the minimum changes in moisture content $(4.00 \%-6.54 \%)$ observed in treatment $\mathrm{P}_{1}$ at $1^{\text {st }}$ to $80^{\text {th }}$ day of storage, respectively.

\section{INTRODUCTION}

Tomato (Solanum lycopersicum L.) belongs to family Solanaceae; is one of the largest produced and consumed vegetable crop in the world. Tomatoes are well known as a health promoter having vitamins and disease fighting phyto-chemicals especially lycopene. Tomatoes are a top source of Vitamin A and C contains more dietary fibre, beta-carotene, iron, lycopene, magnesium, niacin, potassium, phosphorus, riboflavin and thiamine with low in saturated fat, cholesterol and sodium [1]. Tomato is one of the most popular vegetables and ranks first. Tomato and tomato products are the major sources of lycopene and are considered to be important contributors of carotenoids in human diet $[2,3]$. It is one of the most popular salad vegetables in raw taste and is made into soups, conserves, pickles, ketchup, sauces and other products. It is served as raw, baked, stewed, fried and as a sauce with various other foods. It is recognized as one of the most important "Protective Food" both because of its special nutritive value and also because of its wide production [4]. It is highly perishable crop and cannot be stored for the longer period because of higher moisture content resulting around 30$40 \%$ post-harvest losses. Tomato is normally consumed as a fresh vegetable as salad or culinary purpose and around $10 \%$ is being consumed as processed form.

Processing of tomato into market demanded products becomes very necessary to minimize the glut in the market during its peak season of production. The demand by the processing industries of the world for tomatoes continues at a high level. Therefore, it was necessary to utilize tomato for the preparation of dried tomato slices to increase availability over an extended period and to stabilize the price during the glut season. Hence, the present investigation was carried out to assess the effect of different pretreatments and drying methods on moisture percentage of dried tomato slices at ambient/room storage. 


\section{MATERIALS AND METHODS}

The experiment was conducted at Post Graduate Laboratory of Horticulture Department, College of Agriculture, Junagadh Agricultural University, Junagadh, Gujarat (India). The fully ripe, firm and oval shaped tomato fruits of cv. GT-1 of uniform size, free from mechanical damage, bruises and fungal attack were procured from Junagadh market, Junagadh, Gujarat. The fruits were washed with tap water in the R\&D laboratory. Fruits were used for preparation of dried slices with five level of pre-treatment i.e. $\mathrm{P}_{1}$-Peeled by hot water dip blanching, $\mathrm{P}_{2}$-Peeled by hot brine dip blanching, $\mathrm{P}_{3}$ Unpeeled by hot water blanching, $\mathrm{P}_{4}$-Unpeeled by hot brine blanching, $\mathrm{P}_{5}$ Control-without peeled and blanched followed by 2 drying methods i.e. $\mathrm{D}_{1}$-Tray and $\mathrm{D}_{2}$-Sun drying and there were 10 treatment combinations in the experiment. For the pre-treatment, the tomatoes were blanched in hot water at $100^{\circ} \mathrm{C}$ for 30 seconds using $2.5 \%$ brine. After pretreatment, the fruits were sliced to maintain one cm thickness using stainless steel knives and then it was kept on a stainless steel sieve for a few minutes for draining of excess juice and then spreaded uniformly on Stainless Steel tray for drying under sun and tray drier. In tray drier for initial 3 hours, the temperature was maintained at $60^{\circ} \mathrm{C}$ and then, it was reduced to $40^{\circ} \mathrm{C}$ for maintaining quality as well as the moisture content of dried slices. For the sun drying, Trays of tomato slices were kept under the sun at morning 9.00 a.m. to evening 5.00 p.m. and were covered with the double layer muslin cloth to avoid the direct heat to the slices. After both the drying process over, the dried tomato slices were packaged in 200 gauge polyethylene bags and stored at room/ambient temperature.

The total drying time (h) was recorded by calculating the time required to dry the tomato slice up to safe moisture level. Moisture content (\%) of dried tomato slice was calculated by using the standard formula and expressed on per cent basis. The experimental data were analyzed statistically according to the analysis of variance technique as suggested by [5].

\section{RESULTS AND DISCUSSION}

\section{Effect of pre-treatments}

The effect of pre-treatment, $\mathrm{P}_{2}$ recorded minimum (14.50 h) drying time (Figure 1). The maximum drying time (18.83 hr) for drying the slices was recorded under treatment $\mathrm{P}_{5}$. Significantly the minimum moisture content $(4.00,4.40,4.70,5.52$ and $6.54 \%$ ) was observed in treatment $\mathrm{P}_{3}$ at $1,20,40,60$ and $80^{\text {th }}$ day of storage, respectively. Similar results were also reported by Gupta and Nath, in the drying of tomatoes and [7], in nutritional quality and shelf life of dehydrated tomatoes and green chillies $[6,7]$.

While, the maximum moisture content $(4.94,5.34,5.64,6.46$ and $7.48 \%$ ) was recorded in $\mathrm{P}_{5}$ at $1^{\text {st }}, 20^{\text {th }}, 40^{\text {th }}, 60^{\text {th }}$ and $80^{\text {th }}$ day of storage (Figure 2), respectively. The increasing trend might be due to an increase of moisture by the dried tomato slices from the atmosphere [8].

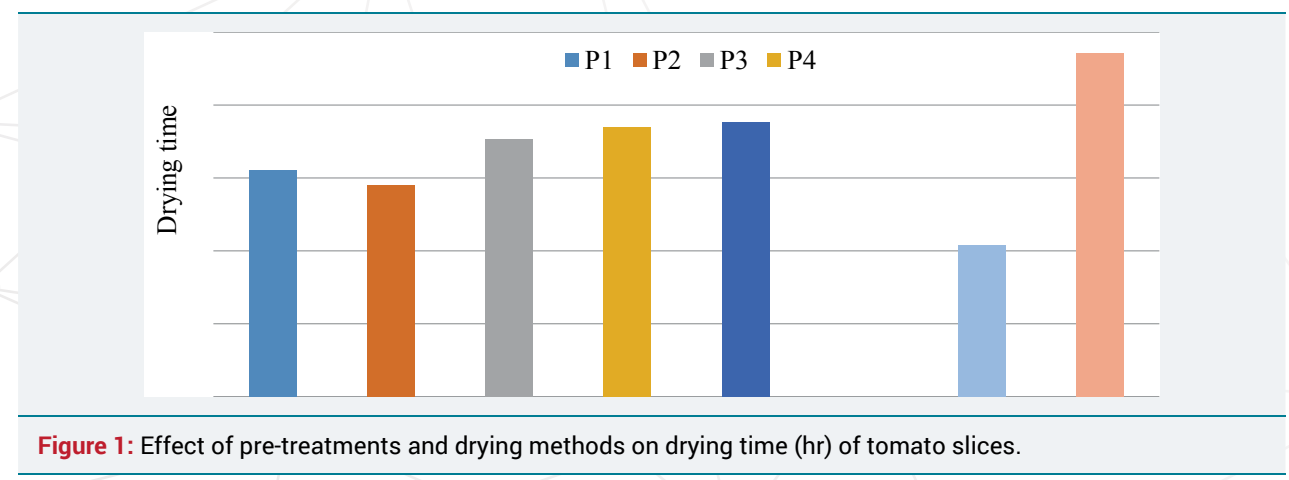




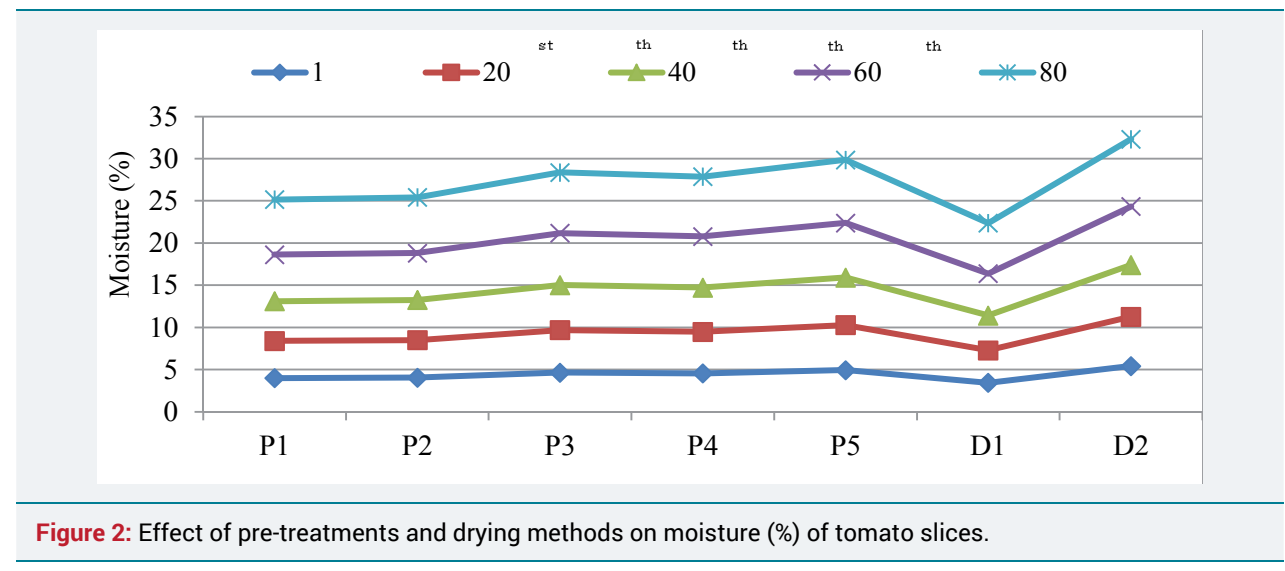

\section{Effect of drying methods}

Cabinet drying $\left(D_{1}\right)$ required minimum time $(10.40 \mathrm{~h})$ for drying of tomato slices while sun drying $\left(\mathrm{D}_{2}\right)$ required maximum time $(23.60 \mathrm{~h})$ for drying of tomato slices. In tray drier, there was intense concentrated heat and the controlled air circulation inside the drier whereas in sun drying there was lower rate of air circulation and diffused heat and no control condition of temperature and relative humidity. Similar results in conformity to these findings were also reported by [6] in the drying of tomatoes.

On the $120,40,60$ and $80^{\text {th }}$ day of storage, the sun dried tomato slices had maximum moisture $(5.43,5.83,6.13,6.95$ and $7.97 \%$, respectively), while tray dried slices notified minimum $(3.44,3.84,4.14,4.96$ and 5.98\%) moisture on 1, 20, 40, 60 and $80^{\text {th }}$ day of storage, respectively. The progressive increase in moisture content was notified in all the samples dried by tray and sun drying method. It might be possibly due to hygroscopic nature of the slices which observed the moisture during storage. Similar results were also reported by Sagar, 2001 for onion slices [8].

\section{Interaction effect of pre-treatments and drying methods}

The data indicating the interaction effect of pre-treatments and drying methods was found non-significant with respect to moisture percentage under the present investigation.

\section{CONCLUSION}

The result of the investigation showed that better quality of dried tomato slice can be pretreated by hot water blanching of tomato at 1000C for 30 seconds using 2.5 $\%$ brine followed by tray drying at temperature $60^{\circ} \mathrm{C}$ for initial $3 \mathrm{~h}$ and $40^{\circ} \mathrm{C}$ for the rest $7.5 \mathrm{~h}$ to get the minimum changes in moisture content during 80 days of storage. Therefore, the treatment combination i.e. peeling of tomato by hot brine dip blanching followed by tray drying can be suggested to the farmers or processors for drying of tomato slice which could make a significant contribution to the food industry.

\section{REFERENCES}

1. Charanjeet K, George B, Deepa N, Singh B, Kapoor HC. Antioxidant status of fresh and processed tomato. J Food Sci and Technology. 2004; 41: 479-486. Ref.: https://goo.gl/VBTpFV

2. Goula AM, Adamopoulos KG. Spray drying of tomato pulp in dehumidified air: I. The effect on product recovery. J Food Eng. 2005; 66: 25-34. Ref.: https://goo.gl/9UkRy

3. Tapiero $\mathrm{H}$, Townsend, DM and Tew $\mathrm{K} \mathrm{D}$. The role of carotenoids in the prevention of human pathologies. Biomed Pharmacother. 2004; 58: 100-110. Ref.: https://goo.gl/J1Nu9w

4. Choudhary B. Vegetables of India. National Trust India. 2001; 40.

5. Gupta RG, Nath N. Drying of tomatoes. J Food Sci Technol. 1984; 21: 372-376

6. Chaturvedi A Reddy, TN Shankaraiah V, Babu JD. J Res ANGRAU. 2003; 31: 90-100.

7. Sagar VT. J Food Sci Technol. 2001, 38: 525-528.

8. Panse VG, Sukhatme PV. 1985. ICAR Pub. New Delhi. 